\title{
Why is Study Stream Gaining Popularity Among Students Worldwide?
}

\author{
Brian Lee \\ Singapore University of Social Sciences, Singapore
}

\begin{abstract}
:
Study Stream is a new online platform where students can join its focus room to study simultaneously with students worldwide. Study Stream claims that they use evidence-based methods to help boost productivity and help people stay focused on study. The science behind this platform includes "Psychology of mimicry and Psychology of accountability.

The platform may work effectively by applying two famous Psychology principles - The Chameleon Effect and The Hawthorne Effect. The Chameleon Effect is a nonconscious mimicry of others' behaviours. A person's perception of the other's specific behaviour will increase the possibility of engaging in that behaviour by himself or herself unintentionally.

When someone goes to a place filled with people studying, such as a library, he or she would likely emulate the behaviour and try to stay focused on his or her study. Study Stream is very much like a digital format of this type of environment or surrounding.

The Hawthorne effect, on the other hand, is our tendency to work harder and perform better when we know that we are observed. Study Stream usually encourages users to switch on their videos. That, as Study Stream claims, would help users "stop checking their phone and hit the books more!"

In addition, home-based learning (HBL) has provided perfect timing for Study Stream. An increasing number of HBL students due to COVID-19 has definitely contributed to the popularity of Study Stream. Students who now need to engage in HBL would find that they have a challenging environment for them to stay focused on their study at home. Study Stream could be a useful platform for them.

The peers may invite them to try Study Stream. That is definitely a pull factor. In addition, parents would be more receptive to their children's switching on Study Stream, rather than playing online games.

All of the above could be the reasons why people employ this method, as it seems to work for some people.
\end{abstract}

Keywords: Online Studying Platform, Study Stream, Zoom. 